\title{
revistadechimie.ro
}

Vol. 73 / Number 1 / Year 2022
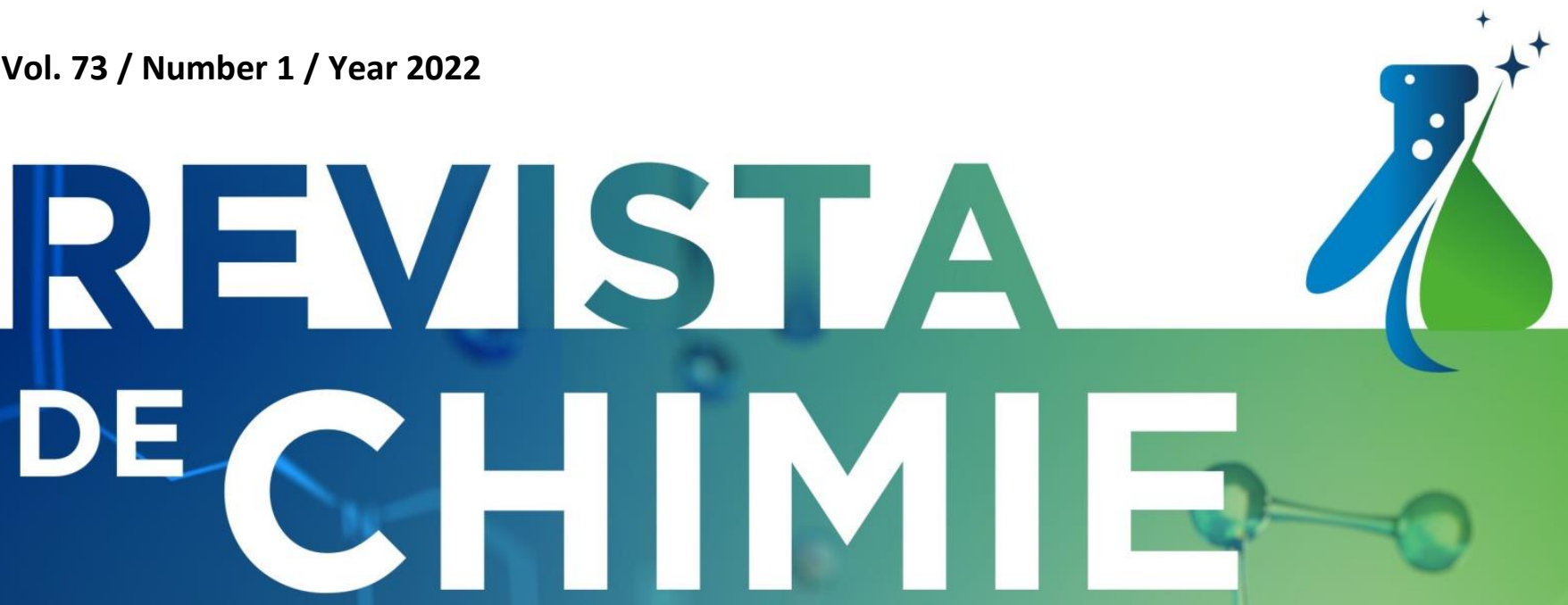

Chemistry Sciences

Chemical and Biochemical Engineering

Environmental Chemistry and Engineering

Chemistry Application in Food, Nutrition, Agriculture

Medical and Pharmaceutical Chemistry

Materials

\section{JANUARY 2022}

Print ISSN: 0034-7752 / Online ISSN: 2668-8212 
REVISTA DE CHIMIE FOUNDED IN 1949

BUCURESTI ROMANIA

EDITORIAL BOARD

Editor-in-Chief:

Gabriel Lucian RADU

Politehnica University of Bucharest, Romania

Editorial Manager:

Ion ANDRONACHE

Revista de Chimie SRL, Bucharest, Romania

\section{EDITORS:}

Ionel MANGALAGIU - Chemistry Sciences

Alexandru Ioan Cuza University, Iasi, Romania

Irinel Adriana BADEA - Chemistry Sciences University of Bucharest, Romania

Costin Sorin BILDEA - Chemical and Biochemical Engineering

Politehnica University of Bucharest, Romania

Ioana FECHETE - Chemical and Biochemical Engineering Université de Technologie de Troyes, France

Gheorghe NECHIFOR - Environmental Chemistry and Engineering Politehnica University of Bucharest, Romania

Simona Gabriela BUNGAU - Environmental Chemistry and Engineering University of Oradea, Romania

Adela PINTEA - Chemistry Application in Food, Nutrition, Agriculture University of Agricultural Sciences and Veterinary Medicine Cluj-Napoca, Romania

Gabriela RAPEANU - Chemistry Application in Food, Nutrition, Agriculture Dunarea de Jos University of Galati, Romania

Gabriel Ovidiu BRATU - Medical and Pharmaceutical Chemistry

Carol Davila University of Medicine and Pharmacy, Bucharest, Romania

Camelia DIACONU - Medical and Pharmaceutical Chemistry

Carol Davila University of Medicine and Pharmacy, Bucharest, Romania

Maria CAZACU - Materials

Petru Poni Institute of Macromolecular Chemistry, Iasi, Romania

Iulian ANTONIAC - Materials

Politehnica University of Bucharest, Romania 
ASOCIATE EDITORS:

Lotfi ALEYA

Université de Franche-Comté, France

Patrick Da COSTA

Sorbonne Universite, France

Remi CHAUVIN

University of Toulouse, France

Huaqiao University, Xiamen Campus, China

Giuseppe GATTUSO

University of Messina, Italy

Andrei JITIANU

Lehman College of The City University of New York, USA

Piotr KURCOK

Centre of Polymer and Carbon Materials Polish Academy of Sciences, Poland

Bouchta SAHRAOUI

University of Angers, UFR Sciences

Institute of Sciences and Molecular Technologies of Angers, France

Yanzhong ZHANG

College of Chemistry, Chemical Engineering \& Biotechnology Donghua University, China

\section{EDITORIAL ADVISORY BOARD:}

\section{Sanda ANDREI}

University of Agricultural Sciences and Veterinary Medicine, Cluj-Napoca, Romania

Narcis BARSAN

Vasile Alecsandri University of Bacau, Romania

\section{Ede BODOKI}

Iuliu Hatieganu University of Medicine \& Pharmacy, Cluj-Napoca, Romania

Andreea BUNEA

University of Agricultural Sciences and Veterinary Medicine, Cluj-Napoca, Romania

Ioan CALINESCU

Politehnica University of Bucharest, Romania

Simona CAPRARESCU

Politehnica University of Bucharest, Romania

Otilia CINTEZA

University of Bucharest, Romania

Simona CLICHICI

University of Medicine and Pharmacy, Cluj-Napoca, Romania

Carolina CONSTANTIN

Victor Babes National Institute, Bucharest, Romania

Lucian Octav COPOLOVICI

Aurel Vlaicu University, Arad, Romania 


\section{Calin Cristian CORMOS}

Babeş-Bolyai University, Cluj Napoca, Romania

\section{Dana CULITA}

Institute of Physical Chemistry Ilie Murgulescu, Bucharest, Romania

Andrei DANET

University of Bucharest, Romania

Iulia Gabriela DAVID

University of Bucharest, Romania

\section{Gyorgy DEAK}

INCDPM, Bucharest, Romania

Kamel EARAR

Dunarea de Jos University of Galati, Romania

Petru FILIP

C. D. Nenitescu Institute of Organic Chemistry, Bucharest, Romania

\section{Anca Irina GALACTION}

University of Medicine and Pharmacy Grigore T. Popa, Iasi, Romania

Maria HARJA

Tehnical University Gheorghe Asachi, Iasi, Romania

\section{Cosmin JINESCU}

Politehnica University of Bucharest, Romania

Vasile LAVRIC

Politehnica University of Bucharest, Romania

\section{Simona Carmen LITESCU}

National Institute for Biological Sciences, Bucharest, Romania

\section{Cristian MATEI}

Politehnica University of Bucharest, Romania

\section{Florin MICULESCU}

Politehnica University of Bucharest, Romania

Maria MOHORA

Carol Davila University of Medicine and Pharmacy, Bucharest, Romania

Lucia MUTIHAC

University of Bucharest, Romania

Denisa NISTOR

Vasile Alecsandri University of Bacau, Romania

\section{Octavian OLARU}

Carol Davila University of Medicine and Pharmacy, Bucharest, Romania

Eliza OPREA

University of Bucharest, Romania

\section{Ovidiu OPREA}

Politehnica University of Bucharest, Romania 
Cristian Valeriu PIRVU

Politehnica University of Bucharest, Romania

Ileana RAU

Politehnica University of Bucharest, Romania

Sonia SOCACI

University of Agricultural Sciences and Veterinary Medicine, Cluj-Napoca, Romania

Bogdan SOCEA

Carol Davila University of Medicine and Pharmacy, Bucharest, Romania

Irina STOIAN

Carol Davila University of Medicine and Pharmacy, Bucharest, Romania

Emanuel VAMANU

University of Agronomical Sciences and Veterinary Medicine, Bucharest, Romania

Camelia VIZIREANU

Dunarea de Jos University of Galati, Romania

Laurian VLASE

University of Medicine and Pharmacy Iuliu Hatieganu, Cluj Napoca, Romania

Maria ZAHARESCU

Institute of Physical Chemistry Ilie Murgulescu, Bucharest, Romania

Romanian Academy

PUBLISHER STAFF:

Alice CRISTEA - Manager

Elena ANDRONACHE - IT

Monica BALUTA - Editing

Iuliana GHITA - Accounting

Impact factor 2019: 1.755 


\section{CONTENTS}

$1 / 2022$

FLAVIA POP, CRISTINA ANAMARIA SEMENIUC

Oxidative Stability of Avocado and Peanut Oils Under Different Heating Temperatures .1

GANG LI, YING WANG, FENGBO WANG

Preparation and Properties of $\mathrm{Mg}(\mathrm{OH})_{2}$ Whiskers by Ion Exchange Resin Method. .9

SIAMAK SHEHNI, SEYED MOSTAFA TABATABAEE GHOMSHEH

Modification Strategy of ZSM-5 Zeolite for Enhancing p-Xylene Selectivity in Toluene Disproportionation.

MENG CUN, JINCHENG MAO, JIZHEN TIAN, MINGJIN CAI, XIAOJIANG YANG, CHONG LIN, ZIGAO HUANG

Multifunctional Surfactant: Integration of Fracturing Fluid Flooding.

ORIANA PALMA CALABOKIS, ROSESTELA PERERA, CARMEN ROSALES, YAMID NUÑEZ, JAIRO SEGURA, ALVARO ARRIETA

Nanocomposite Poly(lactic acid)/sepiolite with Improved Mechanical and Biofilms Formation Properties.

GIOVANNI CHAVES-BEDOYA, EDGAR JOEL VERA, LUZ YINETH ORTIZ-ROJAS

Phytochemical Characterization of Ethanolic Extracts of the Leaves of Zanthoxylum Caribaeum

Lam and Evaluation of Antimicrobial Activity Against Burkholderia Glumae ....

LTAIEF LAMMARI, SANA BEN KHLIFA, LINDA HAMED, KHALIL HAMRAOUI, HASSEN KHARROUBI

Determination of Physical and Mechanical Properties of Potatoes and the Importance in Food Chemistry....

QIAO JING LIN, XUE SUN, JIAN HUA CHEN, JING MEI WANG, WEI WEI LIN, LI JUN FANG

Adsorption of Dibenzothiophene in Gasoline by Si-MCM-41/ Sodium Alginate Porous Hybrid Membrane....

TONG ZUO, YI QIAN, HAONAN ZHANG, JIANBO LIU, LEI GONG, JUN ZHOU, XIAOQI YANG

Impact of $\mathrm{Fe}_{3} \mathrm{O}_{4}$ Nanoparticles on Methane Production from Anaerobic Digestion and Kinetic Analysis....

YANLIANG ZENG, CHUNFA LIAO, ZHENGXIN XU, FUPENG LIU

The Mechanism of Selective Separation of Antimony from Chloride Leachate of Copper Anode Slime....

YU TAN, MINGYU HE, YING LI, MAMATJAN YIMIT

Study on Degradation of Lignin by $\mathrm{TiO}_{2}$-based Photocatalyst Doped with Carbon Dots.

QINWEI JIA, JUN ZHOU, HAONAN ZHANG, TONG ZUO, LUYU WANG, LEI GONG, FENG GENG

Microbial Degradation Pathways of Acrylic Paint Thinner Gas in Biotrickling Filter and

Comparison of Kinetic Models Under Different Gas Concentrations....

Short communication

MARISELVAM AMMASI KRISHNAN, MUTHU RAM PAZHANI SELVAM KAVITHA,

PRAKASH VEERASAMY RADHAKRISHNAN, MURUGESAN GURUSAMY

The Outbreak of the COVID-19 Pandemic and its Healing Effects on the Environment

145

\section{GHEORGHE BENGA}

IN MEMORIAM PETRE T. FRANGOPOL (1933-2020). 